Supporting Information for:

\title{
Solid-State Redox Switching of Magnetic Exchange and Electronic Conductivity in a Benzoquinoid-Bridged $\mathrm{Mn}^{\mathrm{II}}$ Chain Compound
}

\author{
Ie-Rang Jeon, ${ }^{\dagger}$ Lei Sun, ${ }^{\ddagger}$ Bogdan Negru, ${ }^{\dagger}$ Richard P. Van Duyne, ${ }^{\dagger}$ Mircea Dincă, ${ }^{\ddagger}$ \\ T. David Harris ${ }^{\dagger} * *$ \\ ${ }^{\dagger}$ Department of Chemistry, Northwestern University, 2145 Sheridan Road, Evanston IL 60208-3113 \\ ${ }^{\ddagger}$ Department of Chemistry, Massachusetts Institute of Technology, Cambridge, Massachusetts 02139, United States \\ email: dharris@northwestern.edu
}

J. Am. Chem. Soc.

\section{Table of Contents}

Figure S1 | FT-IR spectra of $\mathbf{1}$ and $\mathbf{1}^{\text {red }}$ S2

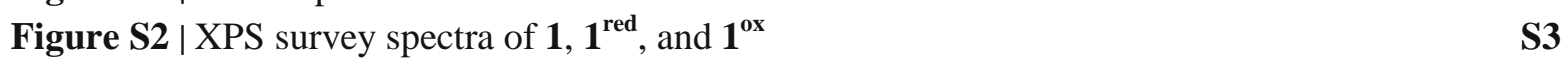

Figure S3 | Diffuse-reflectance UV/Visible spectra of $\mathbf{1}, \mathbf{1}^{\text {red }}$, and $\mathbf{1}^{\mathbf{0 x}} \quad$ S4

Figure S4 | Raman spectra of $\mathbf{1}$ and $\mathbf{1}_{\text {red }} \quad$ S5

Figure S5 | Mn K-edge X-ray absorption spectra of $\mathbf{1}, \mathbf{1}^{\text {red }}, \mathbf{1}^{\text {ox }}$, and $2 \quad$ S6

Figure S6 | I-V curves of $\mathbf{1}$ and $\mathbf{1}^{\text {red }} \quad$ S7 


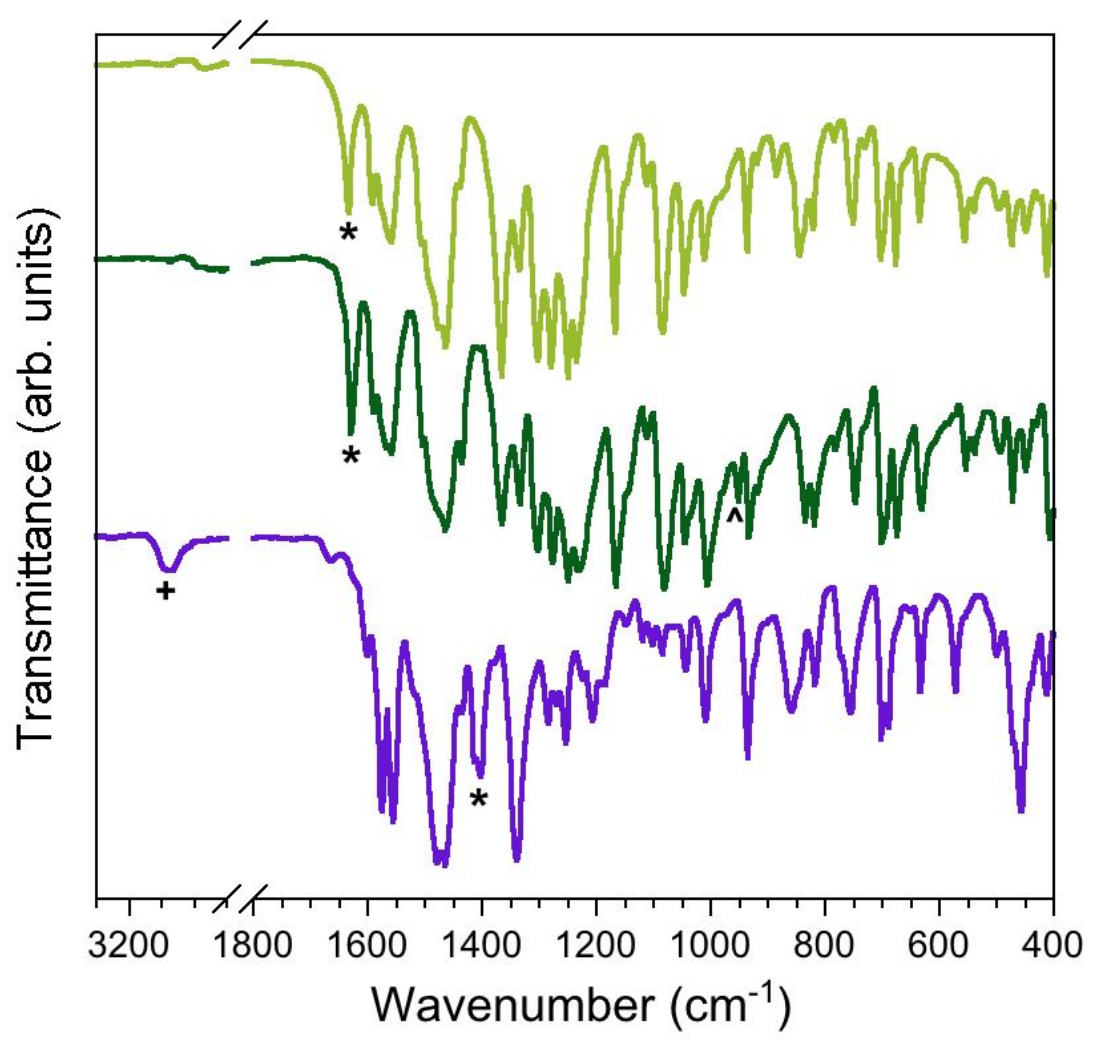

Figure S1 | FT-IR spectra of $\mathbf{1}$ (green), $\mathbf{1}^{\text {red }}$ (purple), and $\mathbf{1}^{\mathbf{o x}}$ (olive) collected at $300 \mathrm{~K}$, highlighting the certain modes of vibrations: $v_{\mathrm{CH}}$ from $\left(\mathrm{Cp}_{2} \mathrm{Co}\right)^{+}(+), v_{\mathrm{CO}}\left({ }^{*}\right)$, and $v_{\mathrm{SO}}(\wedge)$. 


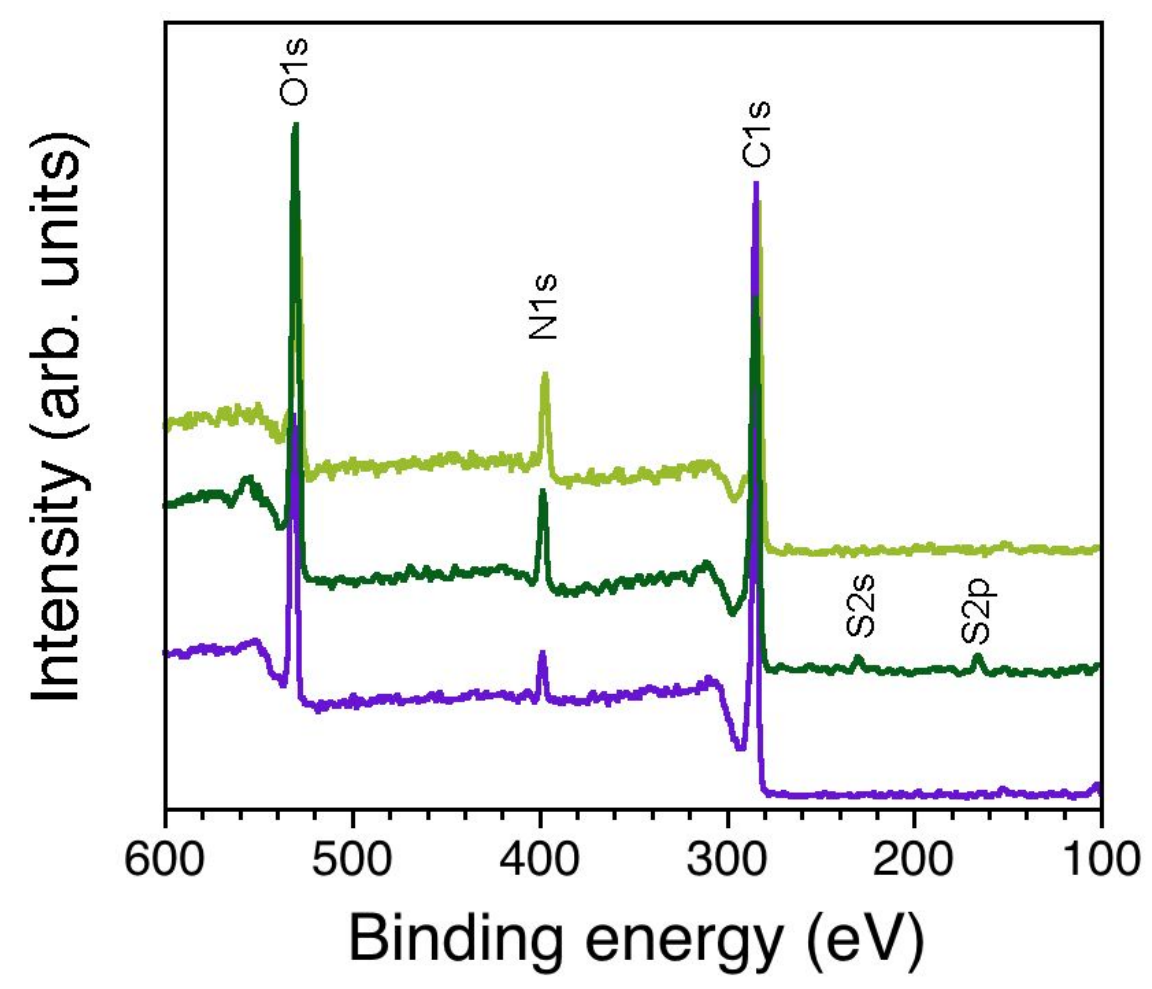

Figure S2 | XPS survey spectra of $\mathbf{1}$ (green), $\mathbf{1}^{\text {red }}$ (purple), and $\mathbf{1}^{\mathbf{o x}}$ (olive) collected at $300 \mathrm{~K}$. 


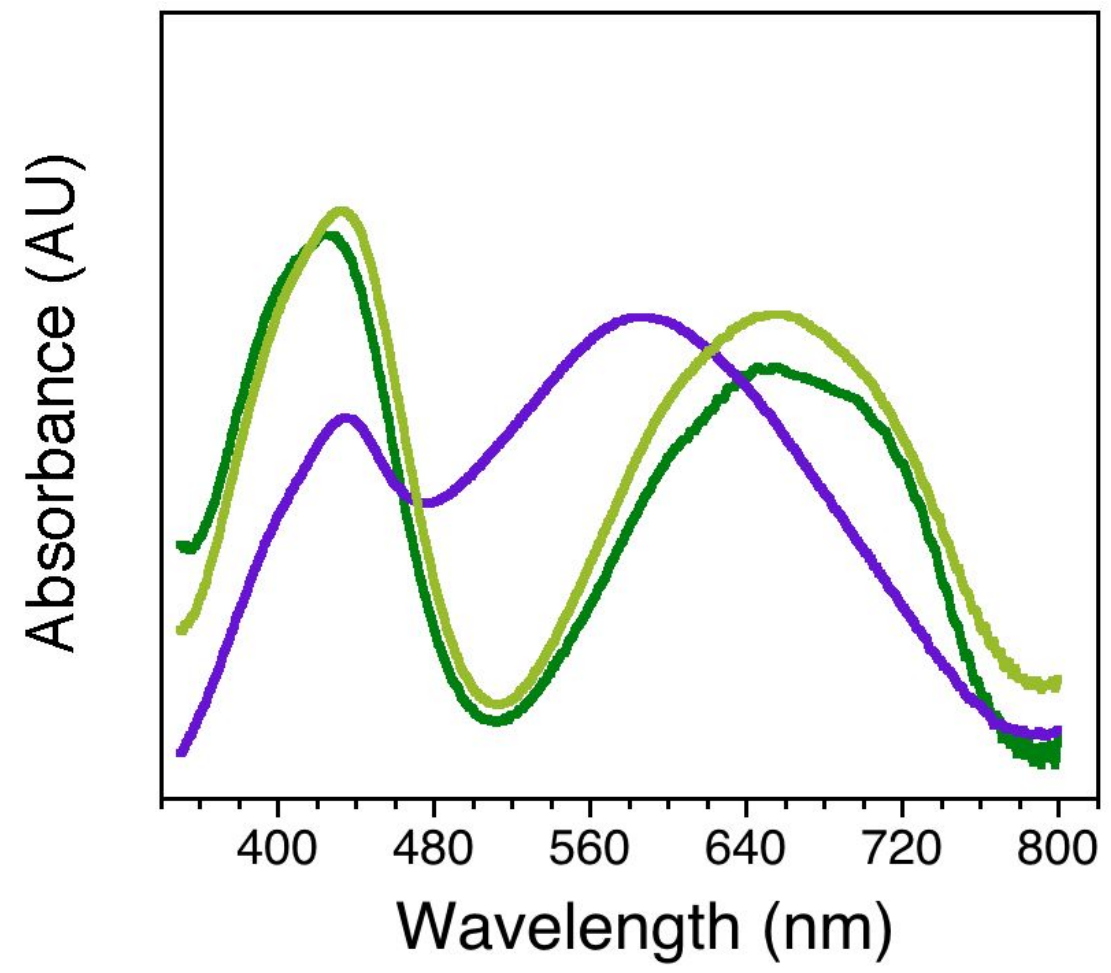

Figure S3 | Diffuse-reflectance UV-Visible spectra of $\mathbf{1}$ (green), $\mathbf{1}^{\text {red }}$ (purple), and $\mathbf{1}^{\mathbf{o x}}$ (olive). 

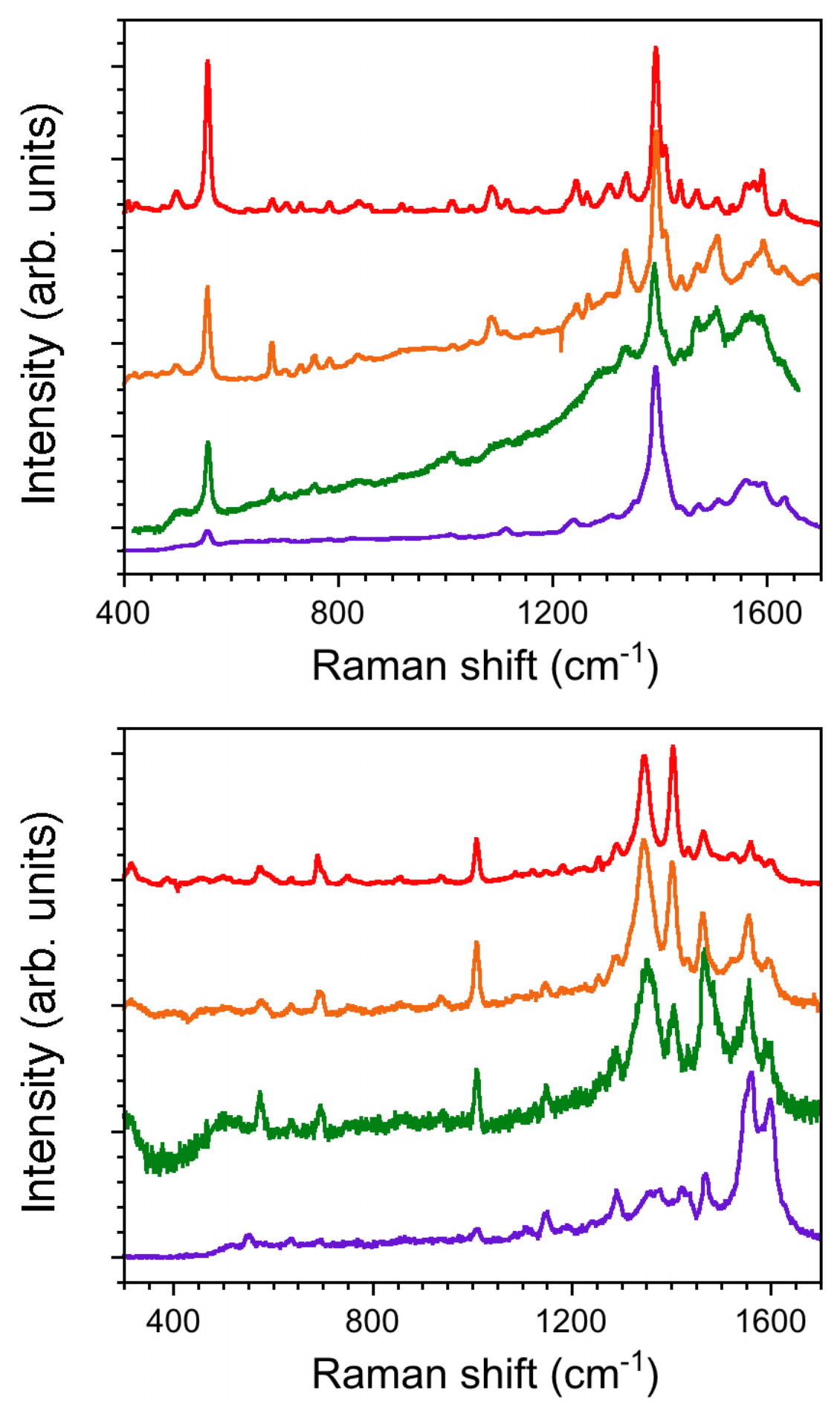

Figure S4 | Raman spectra of $\mathbf{1}$ (top) and $\mathbf{1}^{\text {red }}$ (bottom) collected at $300 \mathrm{~K}$, following excitations at 785 (red), 633 (orange), 532 (green), and 405 (purple) nm. The Raman intensities are adjusted for better comparison between different excitation wavelengths. Note that both the $v_{\mathrm{CO}}$ and $v_{\mathrm{MO}}$ vibrations for $\mathbf{1}^{\text {red }}$ at 1459 and $573 \mathrm{~cm}^{-1}$, respectively, are enhanced with the excitation at $532 \mathrm{~nm}$. 


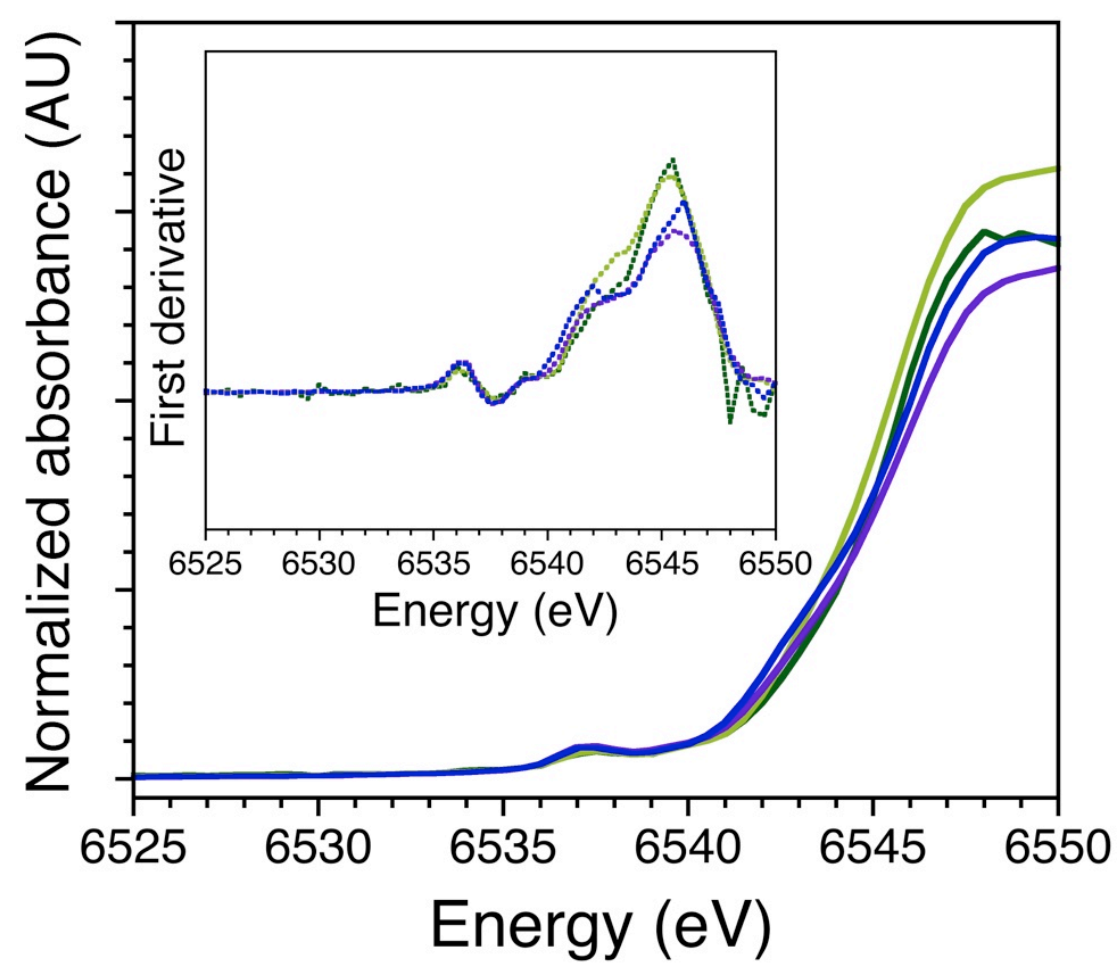

Figure S5 | Mn K-edge X-ray absorption spectra of $\mathbf{1}$ (green), $\mathbf{1}^{\text {red }}$ (purple), $\mathbf{1}^{\mathbf{0 x}}$ (olive), and $\mathbf{2}$ (blue). 


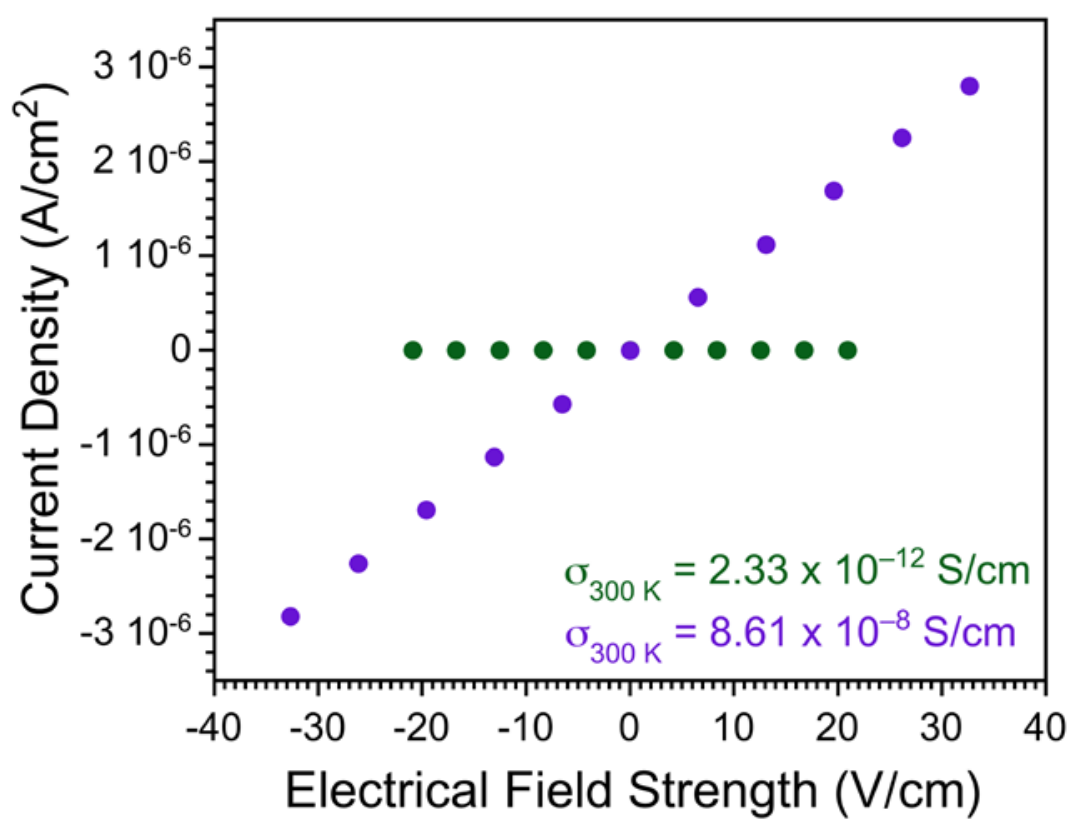

Figure S6 | I-V curves of $\mathbf{1}$ (green) and $\mathbf{1}^{\text {red }}$ (purple) collected at $300 \mathrm{~K}$. 